BRIEF COMMUNICATION OPEN

\title{
Increasing heat and rainfall extremes now far outside the
} historical climate

\author{
Alexander Robinson (iD ${ }^{1,2,3 凶}$, Jascha Lehmann (iD $^{3}$, David Barriopedro (iD) ${ }^{2}$, Stefan Rahmstorf (iD) 3,4 and Dim Coumou (iD) $3,5,6$
}

Over the last decade, the world warmed by $0.25^{\circ} \mathrm{C}$, in-line with the roughly linear trend since the 1970s. Here we present updated analyses showing that this seemingly small shift has led to the emergence of heat extremes that would be virtually impossible without anthropogenic global warming. Also, record rainfall extremes have continued to increase worldwide and, on average, 1 in 4 rainfall records in the last decade can be attributed to climate change. Tropical regions, comprised of vulnerable countries that typically contributed least to anthropogenic climate change, continue to see the strongest increase in extremes.

npj Climate and Atmospheric Science (2021) 4:45 ; https://doi.org/10.1038/s41612-021-00202-w

The year 2020 was marked by a range of intense extreme weather events around the globe, including heat waves and wildfires, heavy rainfall resulting in flooding, and a record-breaking Atlantic Hurricane season. The year started with $377 \mathrm{~mm}$ of rain on January 1st in Indonesia's capital Jakarta, a record amount in observations stretching back to 1866 , causing widespread flooding and displacing 30,000 people ${ }^{1}$. Often, record events result when natural variability and the influence of long-term climate change act in the same direction. For example, La Niña conditions tend to weaken vertical wind shear over the Atlantic and favor Hurricane formation ${ }^{2}$, in agreement with the large number of 30 named tropical storms in 2020. Still, the intensity of the storms, as well as the rapid intensification of 9 of those Hurricanes, are mostly driven by ocean temperatures which have been warming due to longterm climate change ${ }^{3}$.

While this combination of natural variability and long-term climate change fundamentally holds for heat extremes as well, we are now entering an era with heat extremes that simply would not have occurred without climate change. For example, eventattribution analyses have shown that the prolonged heat-wave conditions in both Siberia and Australia in 2020 would have been virtually impossible without climate change ${ }^{4,5}$. The Siberian heat wave resulted in massive forest fires (releasing an estimated 56 Megatons of $\mathrm{CO}_{2}$ ) and infrastructure collapse by permafrost melting ${ }^{4}$, leading to the declaration of a state of emergency. A state of emergency was also declared for the Australian bushfires, associated with the exceptional summer heat from late 2019 to February 2020, also known as the Black Summer ${ }^{6}$. The fires caused disastrous impacts including at least 34 fatalities, hazardous air quality affecting millions of residents, nearly 6,000 buildings destroyed, and the loss of the lives of an estimated $0.5-1.5$ billion wild animals ${ }^{7}$. Meanwhile, the area burned by the Amazon forest fire of 2019 has only been beaten by that of $2020^{8}$. These, as well as record forest fires of 2020 in California and Colorado, were all initiated under periods of extreme heat ${ }^{9,10}$. Also, the record temperatures in parts of the US and Canada in 2021 (with almost $50^{\circ} \mathrm{C}$ at $50^{\circ} \mathrm{N}$ ) have been shown to be virtually impossible without the human-influence on climate ${ }^{11}$. It is becoming increasingly clear that the background conditions driving these destructive, prolonged heat waves only exist due to anthropogenic climate change.

Following the discussion of extreme events in the first decade of this century ${ }^{12}$, here we illustrate what ten years of additional global warming (i.e., from 2011 to 2020) imply for both heat and rainfall extremes around the globe. To do so, we present updated global analyses on (1) normalized monthly temperature anomalies, (2) record-breaking monthly temperatures, and (3) recordbreaking daily rainfall events ${ }^{13-16}$.

Figure 1a shows the global land area experiencing heat extremes of different intensity, from one to four standard deviations above the climatological mean monthly temperature, i.e., 1-sigma to 4-sigma extremes (see "Methods"). During the relatively stable reference period of 1951-1980, the percentages closely follow those expected by Gaussian statistics: 1-sigma extremes are experienced roughly $16 \%$ of the time, 2-sigma extremes about $2 \%$, and 3 -sigma extremes about $0.1 \%$. In the reference period, 4-sigma heat extremes, with an expected probability of $0.003 \%$, are essentially non-existent. In the first decade of this century, 3-sigma extremes became much more prominent in the data, covering $\sim 5 \%$ of land area over 2001-2010 and subsequently increasing to $9 \%$ over 2011-2020. The latter represents a roughly 90 -fold increase compared to the reference period. Moreover, the occurrence of 4-sigma extremes, still nearly absent in the first decade of this century, affected $\sim 3 \%$ of the land area during 2011-2020, reflecting a roughly 1000-fold increase compared to 1951-1980. It is the emergence of this extreme level of anomalous heat that creates events that would have been virtually impossible in a pre-industrial climate (note also that our reference period is substantially warmer than pre-industrial). The above calculations show that the approximately linear global warming trend of $\sim 0.2^{\circ} \mathrm{C} /$ decade results in a nonlinear increase in the number of the highest threshold-exceeding extreme events. For example, after a 1-sigma shift of a Gaussian distribution function, what used to be a 2-sigma extreme becomes 4.5 times more likely, while what used to be a 5-sigma extreme becomes 90 times more likely. $\left(\right.$ see $\left.^{15,16}\right)$. Meanwhile, the increase of recordbreaking extremes over those expected in a stationary climate scales approximately linearly with the trend ${ }^{14}$. Figure $1 \mathrm{~b}$ plots the global-land mean evolution of the ratio of observed local monthly

\footnotetext{
${ }^{1}$ Complutense University of Madrid, Madrid, Spain. ${ }^{2}$ Instituto de Geociencias, CSIC-UCM, Madrid, Spain. ${ }^{3}$ Potsdam Institute for Climate Impact Research, Potsdam, Germany. ${ }^{4}$ Institute of Physics and Astronomy, University of Potsdam, Potsdam, Germany. ${ }^{5}$ Institute for Environmental Studies, Vrije Universiteit (VU) Amsterdam, Amsterdam, Netherlands. ${ }^{6}$ Royal Netherlands Meteorological Institute (KNMI), De Bilt, Netherlands. ${ }^{凶}$ email: robinson@ucm.es
} 

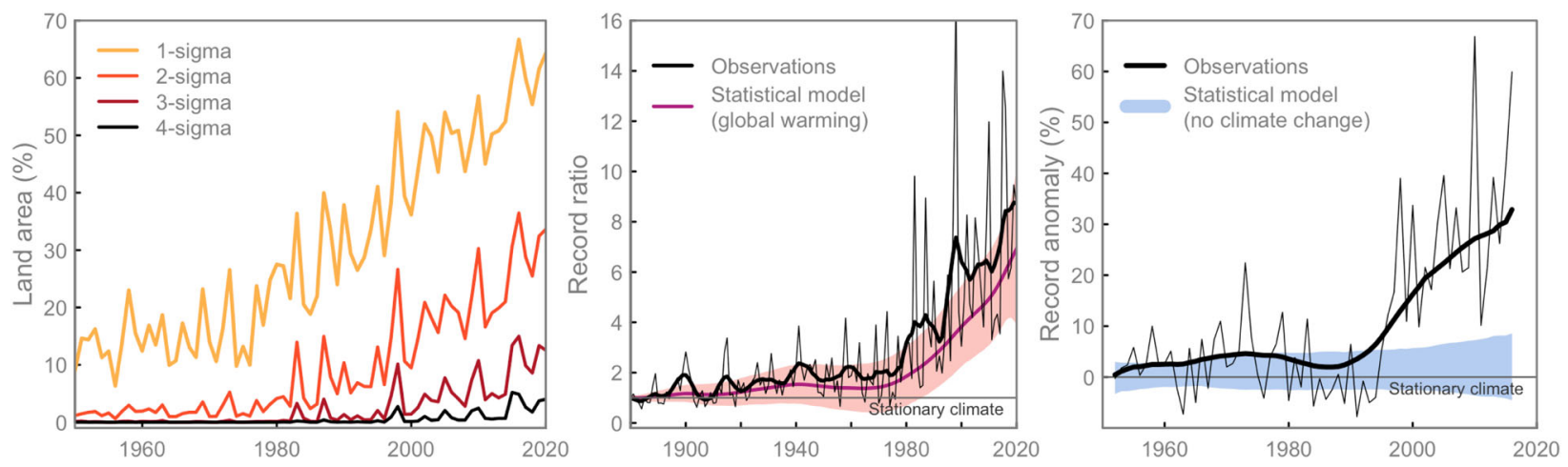

Fig. 1 Trends in climatic extremes. a Percent of the global land area with monthly temperatures above different sigma-thresholds in any calendar month (averaged over the year). b Global annual mean series (1880-2020) of the ratio of observed local monthly temperature records on land compared to those expected in a stationary climate. The thick black line shows the trend with a 10-yr smoothing window, and the magenta line and shading show the median and $90 \%$ confidence interval for the statistical model driven by the long-term global warming trend over land and Gaussian noise. c Deviation series (1950-2016) of the observed number of local daily-rainfall records aggregated over the year and global land areas (in percentage with respect to that expected in a stationary climate). The black line shows the long-term trend. Blue shading shows the $90 \%$ confidence interval for a stationary climate.

temperature records compared to those expected in a stationary climate. The latter scales with $1 / n$, with $n$ the year of the observation. In relatively good agreement with our projections in 2012 , the number of observed record-breaking monthly temperatures has now risen to 8 times those expected in a climate without long-term warming (Fig. 1b). Note that this is much less than the 1000-fold increase in 4-sigma events because the bar for each new record is raised by the previous record.

Figure $2 \mathrm{a}, \mathrm{b}$ shows that the 4-sigma and record-breaking monthly heat extremes are concentrated in tropical regions. This general pattern is also seen for more complex metrics of heatwave events ${ }^{17}$. The low year-to-year variability of monthly temperatures in the tropics $\left(<0.5^{\circ} \mathrm{C}\right)$ compared to the strong long-term warming signal leads to high frequencies of exceptional heat extremes there ${ }^{16,18}$. At higher latitudes, variability is generally higher as well. As temperatures continue to rise, the globalwarming trend will dominate further, and thus frequent extreme heat regimes will expand into higher latitude regions ${ }^{16}$.

From basic thermodynamics, one would also expect a more pronounced increase in rainfall extremes in the wet tropics as compared to higher latitudes. The Clausius-Clapeyron equation states that air can hold $7 \%$ more moisture per degree of warming and daily rainfall extremes roughly scale with this factor ${ }^{13,19}$. In absolute terms, rainfall extremes in warm and moist tropical regions will thus intensify at a stronger rate. Further, tropical rainfall is essentially convective in nature, and expected to increase at substantially higher rates than caused by Clausius - Clapeyron $^{20}$. Such an enhanced tropical rainfall signal still cannot be detected in observations, potentially due to the scarcity of long-running precipitation time series in many tropical regions. When aggregated over sampled land areas, the daily rainfall record anomaly (i.e., the percentage increase in the number of rainfall records compared to a stationary climate) has now reached up to around $+30 \%$ over the last decade, until 2016 (Fig. 1c). This implies that 1 in 4 records are attributable to climate change (1 $\left.P_{0} / P_{1}\right)$.

Since $\sim 1990$, the observed frequency of daily rainfall records has started to deviate significantly and increasingly from that of a stationary climate (i.e., $\sim 0 \%$ in Fig. 1c). This is already observed in many areas of the globe, with statistically significant increases in records in several regions (Fig. 2c). Subtropical dry regions like the western US, southern Africa (and to a lesser extent the Mediterranean and Australia) have seen lower increases in rainfall records than wet regions in the tropics and mid-latitudes.

The straightforward extreme-metrics presented here show that only one decade of additional global warming seriously increases the frequency of heat and rainfall extremes. The land area affected by 3-sigma heat has almost doubled and 4-sigma heat has now newly emerged in the observations. Further, an additional decade of global warming has increased the number of rainfall records by a further 5 percentage points. Although formal attribution studies are still strongly biased towards extra-tropical regions ${ }^{21}$, our results show that tropical regions are experiencing the largest frequency increases in heat and wet extremes, as well as unprecedented events that would have been virtually impossible without climate change. In the coming decade, an upward trend towards more intense and frequent extremes and new heat and precipitation records must be expected, posing critical risks to populations all over the planet.

\section{METHODS}

\section{Temperature analysis}

The temperature data analyzed here were obtained from the Berkeley Earth surface temperature (BEST) global gridded dataset of monthly mean temperature anomalies over land ${ }^{22}$. In order to calculate the normalized temperature anomaly, the following procedure was applied to each month's time series in the dataset ${ }^{16}$. First, the reference temperature was calculated as the average for the period 1951-1980, chosen for its high data availability and relatively stable global climate preceding the approximately linear, predominantly anthropogenic warming trend ${ }^{23}$. Next, we calculated the 30-year smooth trend over the time series using Singular Spectrum analysis with a window half-width of $L=15$. After subtracting the smooth trend, we calculated the standard deviation of the detrended data for the time period 1951-2010. Note that, to improve the robustness of the standard deviation estimate, we use data from the $60-$ year time period, and we included the detrended data from the two bracketing months as well (i.e., to get the July standard deviation, we use detrended monthly data from June, July, and August, $n=180$ data points). This is expected to minimize potential biases in the calculation of the frequency of extremes due to normalization with short samples ${ }^{24}$. Given the reference temperature anomaly $\left(T_{\text {ref }}\right)$ and the standard deviation $\left(T_{\mathrm{sd}}\right)$, we then calculated the normalized temperature anomaly as $T_{\sigma}=\left(T-T_{\text {ref }}\right) /$ $T_{\text {sd }}$. Record-breaking months are those with temperatures exceeding all previous values in the local series. We compare the observed record-ratio with a stochastic model that superimposes white noise with the mean global $T_{\text {sd }}$ to the long-term trend of global warming ${ }^{14}$. Accounting for spatial correlation, we consider that an average of 100 realizations of the stochastic model should be consistent with the global-mean record evolution, which was then divided by the number of records expected in a stationary climate $(1 / n)$. The model was calculated 10,000 times to produce the $90 \%$ confidence interval consistent with the assumption that the increasing record-ratio is driven by a changing background of global warming. 

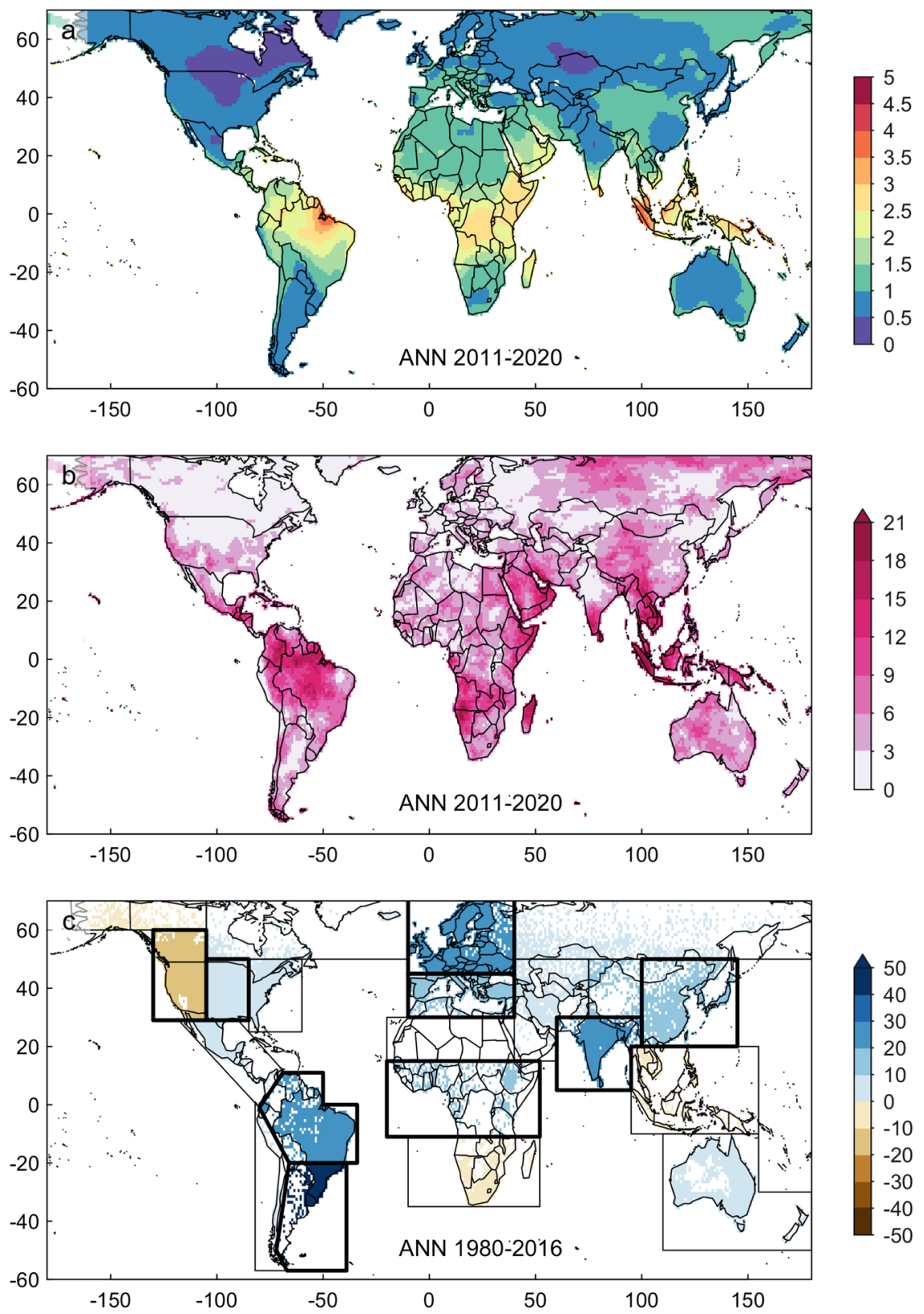

Fig. 2 Extremes and records of the last decade. Top panel: annual mean temperature anomalies (units of $\sigma$ ) for 2011-2020. Middle panel: total number of monthly temperature records for $2011-2020$ (the maximum possible value at each grid point is $120=12$ months $\times 10$ years). Bottom panel: Deviation of observed daily-rainfall records from those expected in a stationary climate (in \%), aggregated for SREX regions and averaged between 1980 and 2016. Regions with statistically significant deviations from a stationary climate are highlighted with bold frames.

\section{Precipitation analysis}

The precipitation data were obtained from the new global land-based Rainfall Estimates on a Gridded Network (REGEN) dataset ${ }^{25}$. This dataset is built from quality-controlled daily rainfall records including two of the largest archives; the Global Historical Climatology Network-Daily (GHCN-Daily) and the Global Precipitation Climatology Center (GPCC) resulting in an unprecedented station density covering the time period 1950-2016. Here, rainfall values from a given grid cell were only considered if it contains at least one measurement station. Recordbreaking rainfall days were determined for each calendar month separately to account for seasonality within a year and then aggregated to annual averages. To quantify how much the observed number of rainfall-records $\left(R_{\text {obs }}\right)$ deviates from that expected in a stationary climate $\left(R_{s}\right)$, we computed the record-anomaly after $N$ years as $R_{\text {anom }}=$ $\left(R_{\text {obs }}-R_{\mathrm{s}}\right) / R_{\mathrm{s}}{ }^{*} 100(\%)$ with $R_{\mathrm{s}}=\Sigma(i / n), 1 \leq n \leq N$. The uncertainty range associated with the stationary climate was determined using the shuffling method as described in detail by Lehmann et al. ${ }^{13}$. Hence, each observational rainfall time series was shuffled 10,000 times to remove possible trends, changes in variance, and autocorrelation resulting in a set of independent and identically distributed (iid) time series under the null hypothesis of a stationary climate.

\section{DATA AVAILABILITY}

All data used for this study are publicly available. The Berkeley Earth temperature anomaly analysis can be found here: http://berkeleyearth.org/data/. The REGEN precipitation dataset is available from here: https://doi.org/10.25914/5ca4c380b0d44.

Received: 20 April 2021; Accepted: 13 September 2021; Published online: 05 October 2021 


\section{REFERENCES}

1. Gokkon, B. Environmental damage exacerbates Jakarta flooding amid record rainfall. https://news.mongabay.com/2020/01/environmental-damage-exacerbates-jakartaflooding-amid-recordrainfall/, (2020). accessed: 2021.

2. Pfleiderer, P., Schleussner, C.-F., Geiger, T. \& Kretschmer, M. Robust predictors for seasonal Atlantic hurricane activity identified with causal effect networks. Weather Clim. Dyn. 1, 313-324 (2020).

3. Bhatia, K. T. et al. Recent increases in tropical cyclone intensification rates. Nat. Commun. 10, 635 (2019).

4. Ciavarella, A. et al. Siberian heatwave of 2020 almost impossible without climate change. https://www.worldweatherattribution.org/siberian-heatwave-of-2020almost-impossible-without-climatechange/, (2020). accessed: 2021.

5. Karoly, D. Record 2020 spring temperature across Australia virtually impossible without human-caused climate change. https://nespclimate.com.au/record-2020spring-event-attribution/, (2020). accessed: 2021.

6. Abram, N. J. et al. Connections of climate change and variability to large and extreme forest fires in southeast Australia. Commun. Earth Environ. 2, 8 (2021).

7. van Oldenborgh, G. J. et al. Attribution of the Australian bushfire risk to anthropogenic climate change. Nat. Hazards Earth Sys. Sci. 21, 941-960 (2021).

8. Andela, N. et al. The Global Fire Atlas of individual fire size, duration, speed, and direction. Earth Syst. Sci. Data 11, 529-552 (2019).

9. Higuera, P. E. \& Abatzoglou, J. T. Record-setting climate enabled the extraordinary 2020 fire season in the western United States. Glob. Change Biol. 27, 1-2 (2021).

10. NOAA. Summer 2020 ranked as one of the hottest on record for U.S. https://www. noaa.gov/news/summer-2020-ranked-as-one-of-hottest-on-record-for-us, (2020). accessed: 2021.

11. Philip, S. Y. et al. Rapid attribution analysis of the extraordinary heatwave on the Pacific Coast of the US and Canada June 2021. https://www.worldweatherattribution. org/western-north-american-extreme-heat-virtually-impossible-withouthumancaused-climate-change/, (2021). accessed: 2021.

12. Coumou, D. \& Rahmstorf, S. A decade of weather extremes. Nat. Clim. Change 2, 491-496 (2012).

13. Lehmann, J., Coumou, D. \& Frieler, K. Increased record-breaking precipitation events under global warming. Clim. Change 132, 501-515 (2015).

14. Coumou, D., Robinson, A. \& Rahmstorf, S. Global increase in record-breaking monthly-mean temperatures. Clim. Change 118, 771-782 (2013).

15. Rahmstorf, S. \& Coumou, D. Increase of extreme events in a warming world. Proc. Natl Acad. Sci. USA 108, 17905-17909 (2011).

16. Coumou, D. \& Robinson, A. Historic and future increase in the global land area affected by monthly heat extremes. Environ. Res. Lett. 8, 034018 (2013).

17. Perkins-Kirkpatrick, S. E. \& Lewis, S. C. Increasing trends in regional heatwaves. Nat. Commun. 11, 3357 (2020).

18. Hawkins, E. et al. Observed emergence of the climate change signal: from the familiar to the unknown. Geophys. Res. Lett. 47, e2019GL086259 (2020).

19. Fischer, E. M. \& Knutti, R. Anthropogenic contribution to global occurrence of heavyprecipitation and high-temperature extremes. Nat. Clim. Change 5, 560-564 (2015).

20. Berg, P., Moseley, C. \& Haerter, J. O. Strong increase in convective precipitation in response to higher temperatures. Nat. Geosci. 6, 181-185 (2013).

21. Harrington, L. J. \& Otto, F. E. L. Reconciling theory with the reality of African heatwaves. Nat. Clim. Change 10, 796-798 (2020).

22. Muller, R. A., Rohde, R., Jacobsen, R., Muller, E. \& Wickham, C. A New estimate of the average earth surface land temperature spanning 1753-2011. Geoinform. Geostat.: An Overview 01, 1000101 (2013).
23. Hansen, J., Sato, M. \& Ruedy, R. Perception of climate change. Proc. Natl Acad. Sci. USA 109, E2415-E2423 (2012).

24. Sippel, S. et al. Quantifying changes in climate variability and extremes: Pitfalls and their overcoming. Geophys. Res. Lett. 42, 9990-9998 (2015).

25. Contractor, S. et al. Rainfall estimates on a Gridded Network (REGEN) - a global land-based gridded dataset of daily precipitation from 1950 to 2016. Hydrol. Earth Syst. Sci. 24, 919-943 (2020).

\section{ACKNOWLEDGEMENTS}

A.R. is supported by the Ramón y Cajal Program of the Spanish Ministry for Science, Innovation, and Universities (grant no. RYC-2016-20587). D.C. is supported by the Netherlands Organization for Scientific Research (NWO), grant 016.Vidi.171011. D.B. acknowledges support from the H2020 EU project CLINT (Grant Agreement No. 101003876).

\section{AUTHOR CONTRIBUTIONS}

S.R. conceived of the study. A.R. and J.L. performed the data processing. All authors contributed to the analysis of the data and writing of the paper.

\section{COMPETING INTERESTS}

The authors declare no competing interests.

\section{ADDITIONAL INFORMATION}

Correspondence and requests for materials should be addressed to Alexander Robinson.

Reprints and permission information is available at http://www.nature.com/ reprints

Publisher's note Springer Nature remains neutral with regard to jurisdictional claims in published maps and institutional affiliations.

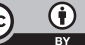

Open Access This article is licensed under a Creative Commons Attribution 4.0 International License, which permits use, sharing, adaptation, distribution and reproduction in any medium or format, as long as you give appropriate credit to the original author(s) and the source, provide a link to the Creative Commons license, and indicate if changes were made. The images or other third party material in this article are included in the article's Creative Commons license, unless indicated otherwise in a credit line to the material. If material is not included in the article's Creative Commons license and your intended use is not permitted by statutory regulation or exceeds the permitted use, you will need to obtain permission directly from the copyright holder. To view a copy of this license, visit http://creativecommons. org/licenses/by/4.0/.

(c) The Author(s) 2021, corrected publication 2021 